XXIII.-On the Aetion of Aldehydes on Phenanthraquinone in Presence of Ammonia. (Third Notice.)

By Francis R. JAYP, M.A., Ph.D., Assistant Professor of Chemistry in the Normal School of Science, South Kensington, and FredK. W. Streatfeild.

\title{
2. Action of Hydroxyaldehydes,
}

Is a former communication (Chem. Soc. J., Trans., 1881, 228), by one of us, in conjunction with Mr. Wilcock, it was mentioned that by the action of salicylaldehyde and ammonia on phenanthraquinone, a compound of the formula $\mathrm{C}_{21} \mathrm{H}_{14} \mathrm{~N}_{2} \mathrm{O}$ was obtained according to the equation-

$$
\begin{aligned}
& \mathrm{C}_{14} \mathrm{H}_{8} \mathrm{O}_{2}+\mathrm{C}_{7} \mathrm{H}_{6} \mathrm{O}_{2}+2 \mathrm{NH}_{3}=\mathrm{C}_{21} \mathrm{H}_{14} \mathrm{~N}_{2} \mathrm{O}+3 \mathrm{OH}_{2} \text {. } \\
& \text { Phenanthra- Salicyl- New } \\
& \text { quinone. aldehyde. compound. }
\end{aligned}
$$

The compound thus formed contained two atoms of nitrogen in the molecule, instead of one, as in the case of the compounds which are formed by the action of non-hydroxylated aldehydes and ammonia upon phenanthraquinone. Thus, in the case of benzaldehyde-

$$
\begin{aligned}
& \mathrm{C}_{14} \mathrm{H}_{8} \mathrm{O}_{2}+\mathrm{C}_{7} \mathrm{H}_{6} \mathrm{O}+\mathrm{NH}_{3}=\mathrm{C}_{21} \mathrm{H}_{13} \mathrm{NO}+2 \mathrm{OH}_{2} \text {. } \\
& \text { Phenanthra- Benz- } \\
& \text { quinone. aldehyde. amidophenanthrole. }
\end{aligned}
$$

The present paper is devoted to an account of the results obtained with hydroxyaldehydes, and with a methoxyaldehyde, upon phenanthraquinone in presence of ammonia.

\section{a. Action of Salicylaldehyde.}

The operation was performed as in the reaction with benzaldehyde (loc. cit., 225). 50 grams of finely-powdered phenanthraquinone were thoroughly mixed in a flask with somewhat more than 1 molecular proportion of salicylaldehyde and an excess of concentrated aqueous ammonia. When heated on a water-bath, the pasty mass fused, then became thick again, and ultimately solidified. During the process of heating, the flask was shaken from time to time until solidification set in. The entire reaction was completed in the course of a few minutes. The brown solid cake was powdered, boiled first with water and then with alcohol, which removed a considerable quantity of colouring matter, and was finally dissolved in boiling amyl alcohol, and the solution decolorised with animal charcoal. From this solution the substance 
was deposited on cooling, in tufts of silky needles. After two or three crystallisations it was quite white, and to all appearance pure. It fused, with blackening and decomposition, about $270-276^{\circ}$. Analysis of the substance dried at $140^{\circ}$ yielded numbers in which the percentage of carbon was somewhat lower than that required by the formula $\mathrm{C}_{21} \mathrm{H}_{11} \mathrm{~N}_{2} \mathrm{O}$. We afterwards found that the substance, on heating with caustic potash, gave off a strong odour of amyl alcohol; so it was evident that, in spite of the high temperature employed in drying, a portion of the solvent had been obstinately retained by the substance. The compound was therefore recrystallised from acetic acid. It had not altered in appearance, but now gave analytical results agreeing well with the theory :---

\begin{tabular}{|c|c|c|}
\hline $1 \ldots \ldots$ & $\begin{array}{c}\text { Substance. } \\
0 \cdot 1094\end{array}$ & $\begin{array}{c}\mathrm{CO}_{2} . \\
0.3258\end{array}$ \\
\hline II $\ldots \ldots$ & $0 \cdot 1130$ & 0.3366 \\
\hline
\end{tabular}

III. 0.0158 gram, burnt with copper oxide in a vacuum, gave 1.15 c.c. (calibrated volume) dry nitrogen, at $18.5^{\circ}$ and under $795.3 \mathrm{~mm}$. pressure, corresponding to $0.001415 \mathrm{gram}$ nitrogen.

\begin{tabular}{|c|c|c|c|c|c|c|c|}
\hline \multirow{3}{*}{\multicolumn{2}{|c|}{$\mathrm{C}_{21}$}} & \multirow{2}{*}{\multicolumn{2}{|c|}{$\begin{array}{l}\text { Calculated for } \\
\mathrm{C}_{. .1} \mathrm{H}_{14} \mathrm{~N}_{2} \mathrm{O}\end{array}$}} & \multicolumn{3}{|c|}{ Found. } & \multirow{3}{*}{$\begin{array}{l}\text { Mean. } \\
81 \cdot 22\end{array}$} \\
\hline & & & & \multirow{2}{*}{$\stackrel{\text { I. }}{81 \cdot 21}$} & \multirow{2}{*}{$\overbrace{81 \cdot 23}^{\text {II. }}$} & \multirow{2}{*}{ III. } & \\
\hline & & 252 & $81 \cdot 29$ & & & & \\
\hline $\mathrm{H}_{14}$ & $\ldots \ldots$ & 14 & $4 \cdot 52$ & $4 \cdot 63$ & $4 \cdot 63$ & - & $4 \cdot 63$ \\
\hline $\mathrm{N}_{2}$ & $\ldots \ldots$ & 28 & $9 \cdot 03$ & - & - & 8.95 & 8.95 \\
\hline \multirow[t]{2}{*}{0} & $\ldots \ldots$ & 16 & $5 \cdot 16$ & 一 & - & - & $(5 \cdot 20)$ \\
\hline & & 310 & $100 \cdot 00$ & - & - & - & $100 \cdot 00$ \\
\hline
\end{tabular}

Properties.-Crystallises in tufts of very fine white needles, but after pressing and drying appears to the unaided eye amorphous. Fuses, with blackening and decomposition, at about 270-276. Alcohol and light petroleum dissolve it slightly on boiling; benzene and carbon disulphide somewhat more readily. The best solvents are glacial acetic acid and amyl alcohol, from hot solutions of which it is deposited on cooling in the tufts of needles just described. It is also very soluble in ether. When boiled with moderately concentrated caustic alkalis, it first fuses to an oil under the liquid, and afterwards solidifies; on employing sufficient liquid, the whole goes into solution as an alkaline salt of the compound. From the alkaline solution, carbonic anhydride and acids precipitate the substance unclianged. Besides thus behaving like a phenol, it seems to possess the properties of a weak base; the addition of a few drops of concentrated 
hydrochloric acid to the ethereal solution precipitates the whole of the substance, but the hydrochloride cannot be isolated, and the substance is insoluble in aqueous hydrochloric acid at ordinary temperatures. Concentrated sulphuric acid dissolves it in the cold, yielding a dirty violet solution with a greenish-blue fluorescence.

By fusion with potash, and by boiling for several days with alcoholic potash, salicylic acid was obtained from the substance, and was identified by the ferrie chloride test. Various unsuccessful attempts were made to obtain the salicylic acid in quantity sufficient for identification by other means. The substance forms with the fused potash a salt, which is not attacked until a temperature is reached at which total decomposition ensues. Milk of lime in sealed tubes at $200^{\circ}$ is without action upon the substance.

Concentrated hydrochloric aeid was without action at $150^{\circ}$; when heated to $200^{\circ}$, the substanee dissolved and crystallised in needles on cooling; at still higher temperatures decomposition took place, but nothing definite could be isolated beyond ammonic chloride.

We also tried to eliminate the oxygen of the substance by means of reducing agents. Distillation of 4 grams with zinc-dust in a current of hydrogen yielded only a minute quantity of a tarry distillate. Hydriodic acid and amorphous phosphorus at lower temperatures were without action; at $200^{\circ}$ a substance with basic properties was obtained, but in quantity too small for investigation, the greater part of the original substance being resinised.

A number of attempts were made to prepare an acetyl-derivative, but neither acetic anhydride-either alone, or with sodie acetate, or with zinc chloride-nor acetyl chloride, had any action upon the substance, though the temperature was raised as high as was possible without total decomposition of the reagent.

Benzoyl-derirative.-Eight grams of the compound were heated in a large boiling-tube with about an equal weight of benzoic anhydride. The temperature was not determined, but was probably a little higher than the boiling point of benzoie acid. The fused mass boiled at first, and benzoic acid collected in the upper part of the tube; afterwards it became pasty, and ceased boiling, upon which the operation was interrupted. The cooled mass was powdered, and extracted several times with small quantities of hot alcohol, in order to remove benzoic anhydride and benzoic acid. A grey pulverulent substance remained, which was dissolved in hot benzene. On cooling, it was deposited in crystals, and after two or three crystallisations, fused constantly at $218-220^{\circ}$. The substance crystallises in two forms-small crystals, apparently cubical, and tufts of needles. Both forms have the same fusing point, and pass readily into each other.

The substance gave on analysis the following results:- 


$$
\begin{array}{cccc} 
& \text { Substance. } & \mathrm{CO}_{2 \cdot} \cdot & \mathrm{OH}_{2} . \\
\mathrm{I} \ldots \ldots & 0 \cdot 1480 & 0 \cdot 4385 & 0 \cdot 0598
\end{array}
$$

II. 0.0548 gram, burnt in a vacuum with copper oxide, gave 3.93 c.c. (calibrated vol.) dry nitrogen at $20 \cdot 2^{\circ}$, and under $635.1 \mathrm{~mm}$. pressure, corresponding to 0.00647 gram nitrogen.

III. 0.0506 gram gave 3.93 c.c. (calibrated vol.) dry nitrogen at $161^{\circ}$, and under $585.0 \mathrm{~mm}$. pressure, corresponding to 0.00358 gram nitrogen.

These numbers lead to the formula of a monobeuzoyl-derivative,

\begin{tabular}{|c|c|c|c|c|c|c|}
\hline \multirow[b]{3}{*}{$\mathrm{C}_{28} \ldots \ldots \ldots$} & \multirow{2}{*}{\multicolumn{2}{|c|}{$\begin{array}{c}\begin{array}{c}\text { Calculated for } \\
\mathrm{C}_{21} \mathrm{H}_{13}\left(\mathrm{C}_{7} \mathrm{H}_{5} \mathrm{O}\right) \mathrm{N}_{2} \mathrm{O}\end{array} \\
.\end{array}$}} & \multicolumn{3}{|c|}{ Found. } & \multirow{3}{*}{$\begin{array}{l}\text { Mean. } \\
80 \cdot 80\end{array}$} \\
\hline & & & \multirow{2}{*}{$\begin{array}{l}\text { I. } \\
80 \cdot 80\end{array}$} & \multirow{2}{*}{ II. } & \multirow{2}{*}{ III. } & \\
\hline & 336 & $81 \cdot 16$ & & & & \\
\hline $\mathbf{H}_{18} \ldots \ldots \ldots$ & 18 & $4: 35$ & $4 \cdot 48$ & - & 一 & $4: 48$ \\
\hline & 28 & $6 \cdot 76$ & - & $7 \cdot 00$ & $7 \cdot 08$ & $7 \cdot 04$ \\
\hline \multirow[t]{2}{*}{$\mathrm{O}_{2} \ldots \ldots$} & 32 & $7 \cdot 73$ & - & - & - & $(7 \cdot 68)$ \\
\hline & 414 & $100 \cdot 00$ & 一 & 一 & - & $100 \cdot 00$ \\
\hline
\end{tabular}
$\mathrm{C}_{21} \mathrm{H}_{13}\left(\mathrm{C}_{7} \mathrm{H}_{5} \mathrm{O}\right) \mathrm{N}_{2} \mathrm{O}:-$

Only the value for nitrogen is decisive in showing whether a monobenzoyl or a dibenzoyl derivative has been formed, or indeed, whether a benzoyl-derivative has been formed at all, as the percentage both for carbon and for hydrogen in these two derivatives and in the original substance differs only very slightly.

Constitution of the Compound $\mathrm{C}_{21} \mathrm{H}_{14} \mathrm{~N}_{2} \mathrm{O}$. - Taking into account the behaviour of this compound in forming with caustic alkalis salts decomposible by carbonic anhydride; the existence of a monobenzoylderivative; the preparation from it of phenanthraquinone and salicylic acid; and lastly, its mode of formation; we are led to the adoption of the constitutional formula-

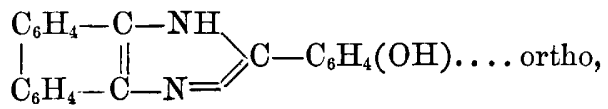

as the best expression of the reactions of this compound. The substance would thus belong to the class of the anhydro-bases described by Hübner, and would be the exact analogue in the phenanthrene series of the compound anhydrosalicyldiamidobenzene-

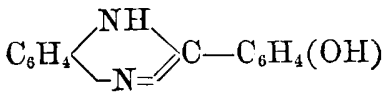

(Hübner and Mensching, Ber., 13, 463; Annalen, 210, 345), which was obtained by the reduction of salicylorthonitranilide. Adopting rOL. XLI. 
the same system of nomenclature, the present compound would receive the name anhydrosalicyldiamidophenanthrene.

The constitutional formula above suggested is, however, open to some objections. The compound of Hübner and Mensching is a base, and forms well characterised salts; in the compound here described, the basic properties are almost obliterated, and this could scarcely have been predicted from the mere substitution of phenanthrylene for phenylene, though a lowering of the basic power might have been expected. Again, the behaviour of the compound towards phosphorus pentachloride and towards acetyl chloride, and its resistance to the action of so powerful a reducing agent as hydriodic acid, scarcely suggest the presence of a hydroxyl-group. (The benzoyl-group might of course equally well replace amidic or imidic hydrogen.) But all the constitutional formulæ in which the hydrogen of the hydroxyl-group in salicyl is represented as replaced by some group of atoms - for example, by the introduction of a closed chain uniting the two ortho-points of the salicyl-group-have still less probability than the above. Further, we have obtained from orthomethoxybenzaldehyde a corresponding compound, and in this case the reaction admits only of the above interpretation. From this methoxy-compound we have obtained the salicyl-compound by replacing methyl by hydrogen.

As it seemed desirable to ascertain whether the anomalous result obtained in the reaction with salicylaldehyde-the introduction of two atoms of nitrogen instead of one, into the molecule of the compound, was due merely to the presence of a hydroxyl-group in the aldehyde, or to the position of this hydroxyl-group in the molecule, it was resolved to extend the reaction to an isomeric hydroxylaldehyde, and also to a methoxyaldehyde.

\section{b. Action of Parahydroxybenzaldehyde.}

The parahydroxybenzaldehyde employed was a beautifully crystallised specimen fusing at $115-116^{\circ}$. The operation was conducted as in the case of salicylaldehyde, and the proportions employed were : 15 grams of the aldehyde to 27 grams of the quinone, with an excess of concentrated aqueous ammonia. The reaction took place exactly in the same manner as in the former case. The crude substance was treated with a warm dilute solution of caustic soda, in which it dissolves readily, any unaltered phenanthraquinone being left behind, and was then precipitated from the filtered solution by carbonic anhydride.

The precipitate was dissolved in hot acetic acid, decolorised by boiling with animal charcoal, and allowed to crystallise. After recrys- 
tallising three or four times from the same solvent, the substance was obtained pure in the form of fine white needles. It did not fuse within the range of the mercurial thermometer, but began to blacken about $300^{\circ}$. Analysis gave the following results :-

$\begin{array}{rccc} & \text { Substance. } & \mathrm{CO}_{2 .} & \mathrm{OH}_{2 .} \\ \text { I } \ldots . . & 0.1303 & 0.3874 & 0.0550 \\ \text { II } \ldots . . & 0.1894 & 0.5635 & 0.0810\end{array}$

III. 0.0602 gram, burnt in a vacuum with copper oxide, gave 5.96 c.c. (calibrated vol.) dry nitrogen at $19 \cdot 6^{\circ}$, and under $594.7 \mathrm{~mm}$. pressure, corresponding to 0.00547 gram nitrogen.

These numbers lead to the formula $\mathrm{C}_{21} \mathrm{H}_{14} \mathrm{~N}_{2} \mathrm{O}$ -

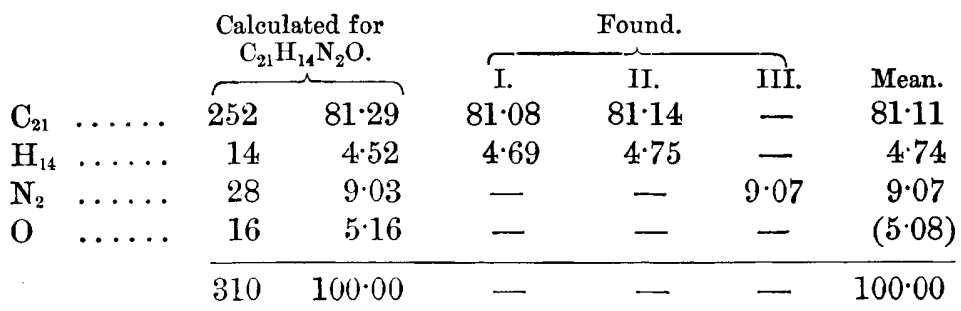

(We found in this case also that the compound, when crystallised from amyl alcohol, gave somewhat too low a percentage of carbon.)

The reaction had therefore taken place exactly as in the case of the ortho-aldehyde, and we will therefore name the compound anhydroparahydroxybenzoyldiamidophenanthrene, attributing to it the constitution-

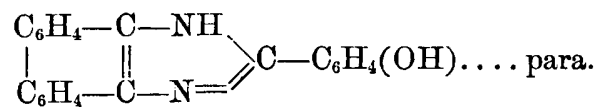

Properties.-Fine white needles, fusing, with decomposition and blackening, above $350^{\circ}$. Soluble in hot glacial acetic acid and amyl alcohol; nearly insoluble in the other ordinary organic solvents, even at their boiling points. Dissolves readily in dilute caustic alkalis, and is precipitated from this solution by carbonic anhydride. Gives no colour reaction with concentrated sulphuric acid.

As in the case of the salicyl-compound, various attempts were made here also to replace the hydroxyl-group by hydrogen. Hydriodic acid and amorphous phosphorus seemed to have as little action upon it as upon the ortho-compound, only a small quantity of a basic substance, similar to that obtained in the former case, being produced, when the heating was continued for several hours at $200^{\circ}$. A distillation with zinc-dust, in which 1 gram of the compound was em. 
ployed, gave a relatively good yield of an oil which solidified when treated with hydrochloric acid, and again liquefied on the addition of potash solution. We intend to repeat this distillation experiment as soon as we have succeeded in preparing a sufficient quantity of the anhydro-compound.

In contradistinction to the ortho-compound it readily forms an acetyl-derivative when treated with acetic ankydride.

Acetyl-derivative.-A portion of the substance was heated in a sealed tube with acetic anhydride at $150^{\circ}$ for seven hours. The contents of the tube were digested for some time in the cold with alcohol, and the liquid was then poured from the crystals, which, after pressing and drying, were dissolved in boiling amyl alcohol. The substance required protracted boiling in order to bring it into solution, and separated rapidly in minute needles from the liquid while still hot. After two or three crystallisations, it fused at $205-210^{\circ}$. The fusing point could not be determined with accuracy as the substance blackened and shrunk together several degrees below its fusing point. The specimen analysed retained a slight greyish tinge, which could not be removed by crystallisation, and the smallness of the quantity of the substance at our disposal precluded the employment of other means of purification. Analysis showed that a monacetyl-derivative had been formed:-

$$
\begin{array}{cccc} 
& \text { Substance. } & \mathrm{CO}_{2} . & \mathrm{OH}_{2} \\
\mathrm{I} \ldots \ldots & 0 \cdot 1612 & 0.4624 & 0.0674
\end{array}
$$

II. 0.0619 gram, burnt in a vacuum with copper oxide, gave 3.93 c.c. (calibrated vol.) dry nitrogen at $17^{\circ}$ and under $765.8 \mathrm{~mm}$. pres-

\begin{tabular}{|c|c|c|c|c|}
\hline & \multirow{2}{*}{\multicolumn{2}{|c|}{$\begin{array}{c}\begin{array}{c}\text { Calculated for } \\
\mathrm{C}_{21} \mathrm{H}_{13}\left(\mathrm{C}_{2} \mathrm{H}_{3} \mathrm{O}\right) \mathrm{N}_{2} \mathrm{O} \text {. }\end{array} \\
.\end{array}$}} & \multicolumn{2}{|c|}{ Found. } \\
\hline & & & \multirow{2}{*}{$\begin{array}{c}\text { T. } \\
78 \cdot 23\end{array}$} & \multirow{2}{*}{ II. } \\
\hline $\mathrm{C}_{23} \ldots$ & 276 & $78 \cdot 41$ & & \\
\hline $\mathrm{H}_{16} \ldots \ldots \ldots$ & 16 & $4: 54$ & $4 \cdot 64$ & - \\
\hline $\mathrm{N}_{2} \ldots \ldots \ldots$ & 28 & $7 \cdot 96$ & - & $7 \cdot 55$ \\
\hline \multirow[t]{2}{*}{$\mathrm{O}_{2} \ldots \ldots \ldots$} & 32 & $9 \cdot 09$ & 一 & - \\
\hline & 352 & $100 \cdot 00$ & - & - \\
\hline
\end{tabular}
sure, corresponding to 0.00468 gram nitrogen.

The acetyl-compound is very soluble in glacial acetic acid, but does not crystallise readily from the solution.

\section{Action of Orthomethoxybenzaldehyde.}

This aldehyde was prepared by the method described by Perkin (Chem. Soc. J., 1867, 418), by heating the sodium-compound of salicyl- 
aldehyde with methyl iodide in alcoholic solution. The product boiled between $230^{\circ}$ and $233^{\circ}$ (uncorr.).

In this reaction, in order to insure as good a yield as possible, the substances were heated to $100^{\circ}$ in sealed tubes. 15 grams of the aldehyde and 30 grams of phenanthraquinone, together with an excess of concentrated aqueous ammonia, were thus heated for one houl. There was no pressure in the tubes on opening. The crude substance was pulverised under water, washed, dried, dissolved in hot benzene, and decolorised by boiling with animal charcoal. The benzene solt?tion on standing deposited small compact crystals, which, when recrystallised from the same solvent, were deposited by more rapid crystallisation in yellow needles fusing constantly at $207-208 \cdot 5^{\circ}$. A further quantity of this substance was obtained by concentrating the original benzene solution. The yellow colour seems to be peculiar to the substance, and not due to an impurity, as it could not be removed or even diminished by further purification. The original motherliquor from the yellow crystals yielded a second substance crystallising in white needles. These, after recrystallising several times from hot benzene, fused constantly at $144.5-145 \cdot 5^{\circ}$. They were then recrystallised from glacial acetic acid, but the fusing point remained unchanged. The yellow compound was formed in rather the larger quantity, but the relative proportions of the two products seemed to vary in different experiments.

The yellow compound yielded the following analytical results :-

$\begin{array}{rccc} & \text { Substance. } & \mathrm{CO}_{2} . & \mathrm{OH}_{2} . \\ \text { I } \ldots . . & 0.1702 & 0.5078 & 0.0770 \\ \text { II } \ldots \ldots & 0.1308 & 0.3916 & 0.0596\end{array}$

III. 0.0640 gram, burnt in a vacuum with copper oxide, gave 5.96 c.c. (calibrated vol.) dry nitrogen at $11.8^{\circ}$ and under $585.7 \mathrm{~mm}$. pressure, corresponding to 0.00553 gram nitrogen.

IV. 0.0857 gram, burnt in a vacuum with copper oxide, gave 7.99 c.c. (calibrated vol.) dry nitrogen at $15.8^{\circ}$ and under $584.2 \mathrm{~mm}$. pressure, corresponding to 0.00729 gram nitrogen.

These numbers lead to the formula $\mathrm{C}_{22} \mathrm{H}_{16} \mathrm{~N}_{2} \mathrm{O}$ :-

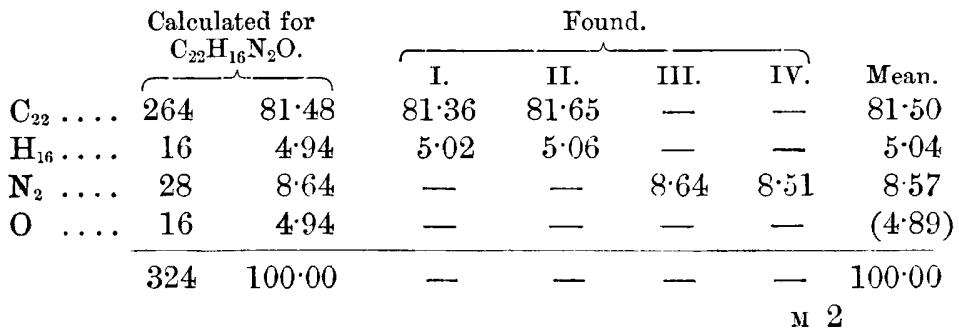


The compound has therefore been formed in a reaction similar to that which takes place in the case of the hydroxyaldehydes. Two molecules of ammonia have taken part in the reaction. The compound is to be regarded as anhydro-orthomethoxybenzoyldiamidophenanthrene,

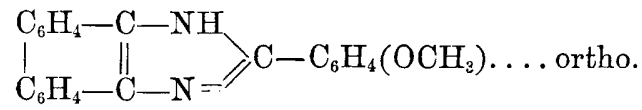

Properties.-Bright yellow needles, fusing at 207-208.5 . Readily soluble in boiling benzene, amyl alcohol, and glacial acetic acid: much less soluble in the cold. Insoluble in dilute acids and in caustic alkalis. Dissolves in cold concentrated sulphuric acid with a blue colour.

A portion of the substance was heated in a sealed tube with concentrated hydrochloric acid. Below $200^{\circ}$ no action took place, except that the substance partly dissolved in the acid and crystallised out on cooling. After heating for some hours at $200^{\circ}$, there was a strong pressure in the tube on opening: the escaping gas burnt with a greenish flame (methyl chloride), and the tube was filled with colourless needles, which, by their fusing point, behaviour towards a solution of caustic potash, and the colour-reaction with sulphuric acid, were identified as anhydrosalicyldiamidophenanthrene, which had thus been formed by the substitution of hydrogen for methyl in the yellow compound. This reaction, as we have already pointed out, leaves no room for doubt as to the constitution of the salicyl-compound.

In the case of the white compound fusing at $144.5-145.5^{\circ}$ the following results were obtained on analysis :-

$$
\begin{aligned}
& \text { Substance. } \quad \mathrm{CO}_{2} . \quad \mathrm{OH}_{2} \text {. } \\
& \begin{array}{llll}
\text { I } \ldots \ldots & 0.1141 & 0.3400 & 0.0489
\end{array} \\
& \text { II ..... } 0.0972 \quad 0.2888 \quad 0.0414
\end{aligned}
$$

III. 0.0548 gram, burnt with copper oxide in a vacuum, gave 2.90 c.c. (calibrated vol.) dry nitrogen at $15.7^{\circ}$ and under

\begin{tabular}{|c|c|c|c|c|c|c|}
\hline \multirow[b]{3}{*}{$\mathrm{C}_{23} \ldots \ldots$} & \multirow{2}{*}{\multicolumn{2}{|c|}{$\begin{array}{l}\begin{array}{c}\text { Calculated for } \\
\mathrm{C}_{22} \mathrm{H}_{15} \mathrm{NO}_{2} \text {. }\end{array}\end{array}$}} & \multicolumn{3}{|c|}{ Found. } & \multirow{3}{*}{$\begin{array}{l}\text { Mean. } \\
81 \cdot 15\end{array}$} \\
\hline & & & \multirow{2}{*}{$\begin{array}{c}\text { I. } \\
81 \cdot 26\end{array}$} & \multirow{2}{*}{$\begin{array}{l}\text { II. } \\
81.03\end{array}$} & \multirow{2}{*}{ III. } & \\
\hline & 264 & $81 \cdot 23$ & & & & \\
\hline $\mathrm{H}_{15} \ldots \ldots$ & 15 & $4 \cdot 62$ & $4 \cdot 76$ & $4 \cdot 73$ & - & 4.75 \\
\hline$\ldots \ldots$ & 14 & $4: 31$ & - & - & $4 \cdot 64$ & $4: 64$ \\
\hline $\mathrm{O}_{2} \quad \ldots \ldots$ & 32 & $9 \cdot 84$ & - & - & - & $(9 \cdot 46)$ \\
\hline & 325 & $100 \cdot 00$ & - & - & - & $100 \cdot 00$ \\
\hline
\end{tabular}
$561.9 \mathrm{~mm}$. pressure, corresponding to 0.00255 gram nitrogen.

These figures lead to the formula $\mathrm{C}_{22} \mathrm{H}_{15} \mathrm{NO}_{2}$ :- 
The reaction in this case is similar to that which occurs with benzaldehyde and other non-hydroxylated aldehydes. Only one molecule of ammonia takes part in the reaction. The compound is therefore orthomethoxybenzenylamidophenanthrole-<smiles>CCCCCc1oc(CCOCCOCCCC)nc1CC</smiles>

Properties.-White needles, fusing at $144.5-1455^{\circ}$. Readily soluble in hot benzene, amyl alcohol, and glacial acetic acid; much less soluble in the cold; is less rapidly deposited from its solutions than the yellow compound; insoluble in dilute acids and in caustic alkalis; dissolves in cold concentrated sulphuric acid, with a greenish colour.

\section{Summary.}

The general results obtained in the investigation of the action of aldehydes upon phenanthraquinone in presence of ammonia, as contained in this and former communications, may be sammed up as follows :-

The reaction varies with the nature of the aldehyde employed.

1. With aldehydes of the benzene series the reaction takes place according to the equation-

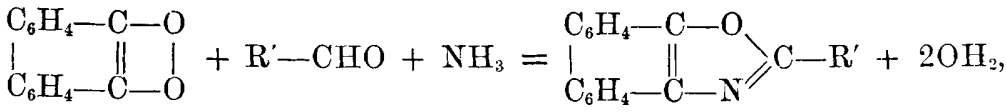

Phenanthra-

quinone.

in which $R^{\prime}$ represents a monad radicle of the phengl series. Ordinary fatty aldehydes cannot be employed in this reaction; but furfuraldehyde, in accordance with its general chemical behaviour, acts like an aldehyde of the benzene series. The compounds formed belong to the class of substances which Ladenburg obtained (Ber., 9, 1524) by the action of anhydrides or chlorides of monobasic acids upon orthoamidophenol, and in which a triad radicle of the form $\mathrm{R}^{\prime}-\mathrm{C} \equiv$ replaces the three atoms of hydrogen in the amidogen- and hydroxyl-groups of the amidophenol.

2. When hydroxyaldehydes of the benzene series are employed, the reaction takes place as follows :-

$$
\begin{aligned}
& {\stackrel{\mathrm{C}}{6} \mathrm{H}_{4}-\underset{\mathrm{C}}{\mathrm{C}_{4}-\mathrm{C}-\mathrm{O}} \stackrel{\mathrm{C}}{\|}-\mathrm{O}}_{\mathrm{O}}^{\mathrm{O}}+\mathrm{R}^{\prime \prime}(\mathrm{OH})-\mathrm{CHO}+2 \mathrm{NH}_{3}= \\
& \begin{array}{l}
\mathrm{C}_{6} \mathrm{H}_{4}-\mathrm{C}-\mathrm{NH} \\
\mathrm{C}_{6} \mathrm{H}_{4}-\mathrm{C}-\mathrm{C}-\mathrm{N}=
\end{array}
\end{aligned}
$$


the compound formed belonging to the class of the anhydro-bases described by Hübner. It seems in this reaction as if the presence of the electronegative hydroxyl-group in the aldehyde attracted a larger quantity of the electropositive ammonia, causing it to take part in the formation of the new molecule.

3. With a methoxyaldehyde (the behaviour of the methyl ether of salicylaldehyde has alone been studied), both the above reactions take place simultaneously, and a mixture of the two compounds belonging to the two classes is obtained, the one componnd differing from the other only by the substitution of the imidogen-group for oxygen. The methoxyl-group probably stands, as regards its electrochemical properties, intermediate between hydrogen and hydroxyl; and as a fact, the reaction of the methoxyaldehyde is a combination of the reactions of the ordinary aldehyde and the hydroxyaldehyde.

In conclusion, it may be pointed out that the above reactions, which may be regarded as condensations in the ortho-series, are most readily accounted for on the assumption that phenanthraquinone possesses the peroxide constitution ascribed to it by Graebe, as expressed in the above formula (see also Chem. Scc. J., Trans., 1880, 410).

One of us is at present engaged, in conjunction with Mr. H. H. Robinson, in studying the action of ammonic formate upon phenanthraquinone. It was thought that the formic acid might play the part of an aldehyde. As the reaction, however, differs in some respects from those here described, it will form the subject of a future communication.

We have also found that phenanthraquinone, acetone, and ammonia react with great readiness upon each other at ordinary temperatures, evolving heat and forming a crystalline compound. Since in the aldehyde reactions described in the present paper, the hydrogen of the aldehydic group $\mathrm{CHO}$ is eliminated, the reaction with acetone must possess an essentially different character. We are at present investigating the subject, and intend also to examine the action of other ketones in this respect. 